metabolic adjustments are still being studied in 24 of our patients.

Our decision to confine surgery to the bypass procedure and to leave gallstones was wrong: patients soon after bypass are not good operative risks. We also think that subcutaneous heparin might be better in preventing deep vein thrombosis than pneumatic leg stimulation.

We thank our numerous and devoted medical and nursing assisttants and the departments of chemical pathology and haematology, without whose help this work could not have been done.

T.R.E.P. and A.H.C. were supported by M.R.C. grant no. G. $972 / 797 /$ C.

\section{References}

Baddeley, M. (1973). Proceedings of the Royal Society of Medicine, 66, 1098. Holzbach, R. T., et al. (1974). New England fournal of Medicine, 290, 296. Kemsley, W. F. F. (1951-2). Annals of Eugenics, 16, 316. Payne, J. H., and DeWind, L. I. (1969) American fournal of Surgery, 118,

Payne, J. H., et al. (1973). Archives of Surgery, 106, 432.

Quaade, F. J., et al. (1971). Scandinavian fournal of Gastroenterology, 6, 537. Salmon, P. A. (1971). Surgery, Gynecology and Obstetrics, 132, 965.

Scott, H. W., and Law, D. H. (1969). American fournal of Surgery, 117, 246. Scott, H. W., et al. (1971). Annals of Surgery, 174, 560.

Solow, C., Silberfarb, P. M., and Swift, K. (1974). New England Fournal of Medicine, 290, 300.

Weismann, R. E. (1973). American fournal of Surgery, 125, 437.

\title{
Beneficial Effects of Jejeunoileostomy on Compulsive Eating and Associated Psychiatric Symptoms
}

\author{
COLIN BREWER, HOWARD WHITE, MICHAEL BADDELEY
}

British Medical fournal, 1974, 4, 314-316

\begin{abstract}
Summary
During a study of 72 patients submitted to jejeunoileostomy for obesity seven were found in whom compulsive, episodic overeating was associated with depressive mood disturbance. When followed up nine to 27 months after operation all seven had lost weight and had also lost the habit of compulsive eating. In all cases psychiatric symptoms improved or disappeared, and symptom substitution was not observed. Obesity rather than psychiatric disorder is usually the main problem in such patients. The implications for psychoanalytic and other concepts of obesity are discussed.
\end{abstract}

\section{Introduction}

The management of obesity is not easy and psychiatrists do not usually succeed when physicians have failed. A modest degree of success is generally accepted for non-medical methods, which rely mainly on group pressures, such as Weight Watchers, and a behavioural approach has shown some promise (Levitz and Stunkard, 1974), but there are still many fat people who fail in their efforts to lose weight or who succeed only transiently.

Surgical methods of weight reduction, notably jejeunoileostomy, are usually successful in achieving and maintaining weight loss (Baddeley, 1973; Payne et al., 1973; British Medical fournal, 1974) but are still regarded as a last resort. In our experience they are also widely criticized. Apart from the purely medical objections, which involve balancing the risks of the procedure and its consequences against the not inconsiderable risks of remaining fat, criticism is of two kinds. \footnotetext{
Department of Psychiatry, University of Birmingham, Birmingham
B15 2TH COLIN BREWER, M.R.C.PSYCH., Lecturer

General Hospital, Birmingham

HOWARD WHITE, M.R.C.PSYCH., Consultant Psychiatrist MICHAEL BADDELEY, F.R.C.S., Consultant Surgeon
}

The first, which is especially common among physicians and general practitioners, stems from those who seem to feel that such operations are in some way morally wrong since fat people can thus escape what are seen as the natural consequences of their own greed or lack of self-control. "She wants to eat her cake and have it too," is a frequent theme.

The second kind of criticism is voiced by those who see obesity as largely due to an underlying emotional disorder. It is implied that to treat the "symptom" without treating the psyche is to invite disaster. Those of a psychoanalytic persuasion claim that obesity has a "defensive" function against feelings of insignificance or frailty (Wittkower, 1971). According to Glucksman (1972), who has recently reviewed the abundant literature on the psychiatric aspects of obesity, "Weight loss represents a serious psychiatric risk for patients with severe psychopathology. They may benefit more from psychotherapy than from weight reduction." There is a close similarity between such objections and the confident predictions of a few years ago that the treatment of phobias, obsessional states, and other psychiatric disorders with behavioural methods would lead to symptom substitution and failure (Eysenck and Wilson, 1974). The well-documented inaccuracy of these predictions (Rachman, 1971) must cast considerable doubt on the theories which gave rise to them. Nevertheless, we were interested to discover the effect of jejeunoileostomy, performed for weight reduction, on certain kinds of abnormal eating behaviour which are apparently related to emotional disturbance. We were also interested in the effect on the disturbance itself.

In the course of a prospective and retrospective study of 72 grossty obese patients submitted to jejeunoileostomy we found seven who experienced before operation an irresistible desire to eat especially large quantities of food when angry, miserable, or tense. These eating "sprees" varied in duration and frequency, but because they went counter to the patients' professed constant desire to lose weight they were usually followed by guilt and despair, which often led to another spree, and so on-sometimes literally ad nauseam.

\section{Case Reports}

Case 1.-The weight of this 55-year-old woman had dropped from 23 st $7 \mathrm{lb}(149.1 \mathrm{~kg})$ to 17 st $(107.9 \mathrm{~kg})$ when she was seen 18 
months after operation. She had no history of psychiatric consultation but had been frequently unhappy and apathetic for many years and used to have two or three eating sprees a week. Since her operation she had had no sprees for over a year, and her mood, confidence, activity, and libido had improved greatly. She had had one isolated spree after 14 months when her husband was ill. Her improvement was confirmed by her husband.

Case 2.-When seen nine months after operation this 43-year-old woman's weight had dropped from 17 st $(107.9 \mathrm{~kg})$ to $11 \mathrm{st}(69.8$ $\mathrm{kg}$ ). She had been obese since the birth of a mongol child 12 years earlier. She was depressed because of obesity and depression was aggravated by the strain of caring for her handicapped child. Four years earlier she had had 12 months' psychiatric treatment as a day patient, without improvement. She had made one suicide attempt. She had a large appetite with sprees when particularly depressed. Since the operation her appetite was smaller, she had no sprees, and was not significantly depressed. Her self-confidence and libido increased, and her husband was delighted; "She's a new woman."

Case 3.-Nine months after operation this 34-year-old woman's weight had reduced from 21 st $6 \mathrm{lb}(136 \mathrm{~kg})$ to $16 \mathrm{st} 4 \mathrm{lb}(103 \mathrm{~kg})$. She had been obese since childhood and had had inpatient psychiatric treatment when she was 17 for depression attributed to obesity. She had had no subsequent treatment but was often depressed and often had eating sprees when in this mood. Since jejeunoileostomy she had had no sprees though her appetite was still hearty. Her husband confirmed and approved of the change.

Case 4.-One year after operation the weight of this 29-year-old woman had dropped from $21 \mathrm{st}(133.3 \mathrm{~kg})$ to $12 \mathrm{st} 10 \mathrm{lb}(80.7 \mathrm{~kg})$. She had had no psychiatric treatment but was increasingly depressed for six months before the operation and mildly paranoid. She indulged in frequent sprees and much nibbling between meals. Since jejeunoileostomy there had been no nibbling or sprees. She was more confident and her marriage was happier. Previously too embarrassed to take a job, she now works as a barmaid.

Case 5.- Seen 27 months after operation this 26-year-old woman's weight had reduced from $18 \mathrm{st} 7 \mathrm{lb}(117.5 \mathrm{~kg})$ to $11 \mathrm{st}$ $(69.8 \mathrm{~kg})$. She had been overweight since childhood and there was a strong family history of obesity. She had had marital problems for years, culminating in divorce before operation. She had been treated for depression by her general practitioner, was often tearful, and had frequent sprees when upset. Since jejeunoileostomy she was hardly ever depressed and had no sprees. Despite satisfactory weight loss her body image was slow to change and she still disliked being photographed and going through turnstiles, but this feeling is gradually lessening.

Case 6.-The weight of this 35-year-old woman, seen 21 months after operation, had dropped from $17 \mathrm{st}(107 \mathrm{~kg})$ to $8 \mathrm{st} 2 \mathrm{lb}(51.7$ $\mathrm{kg}$ ). She had had an unhappy childhood and adolescence and had indulged in eating sprees for many years. She had longstanding marital problems, and had had five years of intensive but unsuccessful psychotherapy before operation. Since jejeunoileostomy she had no sprees and a normal appetite, became more confident, and more readily conceded and discussed the problems in her marriage. Psychotherapy continued, but her therapist confirmed the improvement and was agreeably surprised by it.

Case 7.- Seen eight months after operation this 37-year-old woman's weight had reduced from $19 \mathrm{st} 7 \mathrm{lb}(123.8 \mathrm{~kg})$ to $13 \mathrm{st} 5 \mathrm{lb}$ $(84.8 \mathrm{~kg})$. She had been obese since childhood. She had had no psychiatric treatment but was often depressed and argumentative, which led to eating sprees. Since operation she has been much more tolerant and even tempered, with no sprees.

\section{Discussion}

In all seven cases a long-standing pattern of episodic compulsive eating was rapidly abolished by jejeunoileostomy. Follow up for nine to 27 months showed only one transient relapse. The associated affective disturbance was greatly improved in almost every case, and in no case was it made worse. Symptom substitution did not occur. With the exception of the patient in case 6 the improvement occurred in the absence of any psychiatric or psychopharmacological intervention.

Previous reports (Harris and Frame, 1968; Wittkower, 1971; Solow et al., 1974) from North America, where experience of jejeunoileostomy in this context is greater than in
Britain, have largely agreed on the general and-from the psychoanalytic standpoint-unexpected freedom from adverse psychiatric effects after operation. It is probably significant that the author of the sole report (Wittkower, 1971) which expresses fears about the psychiatric consequences of the procedure seems to have a psychoanalytic orientation.

All the patients reported in previous studies were unselected in terms of psychiatric morbidity. Our findings are even more damaging to psychoanalytic theory since the seven patients described here may be considered an especially vulnerable group. All reported depression and four of them had a history of psychiatric treatment. In contrast, only five out of the other 65 patients we have studied so far had received psychiatric treatment. We feel that the successful outcome in this vulnerable group is particularly convincing evidence of the psychiatric safety of jejeunoileostomy.

Recently, Green and Rau (1974) have suggested that compulsive eating may be an epileptic manifestation and repont improvement in some cases after anticonvulsant therapy. We did not arrange any E.E.G. studies and cannot therefore say whether our patients had the $14 / \mathrm{sec}$ and $6 / \mathrm{sec}$ spike pattern seen in their cases, but the disappearance of compulsive eating patterns in all our patients makes an epileptic aetiology seem rather unlikely. Our experience with another patient is of interest in this respect.

A 29-year-old man developed hyperphagia and polydipsia, which were especially marked when he was depressed, after a severe head injury at the age of 19 , when a right temporal lobe haematoma was evacuated. His weight increased from 16 st $(101.6 \mathrm{~kg})$ before the accident to 31 st $(196.8 \mathrm{~kg})$ before jejeunoileostomy, and he also developed temporal lobe seizures with occasional grand mal attacks. E.E.G. showed a clear right frontotemporal focus. Four-and-a-half months after operation his weight had fallen to $22 \mathrm{st}(139.7 \mathrm{~kg})$ and both the hyperphagia and the polydipsia disappeared. His colleagues confirmed that his mood was greatly improved, and he reported a marked reduction in seizures, which may be due in part to better co-operation in taking his anticonvulsants.

The reasons for the disappearance of the compulsion are not clear. It seems to occur immediately after operation. The dietary restrictions of the immediate postoperative period, which are enforced by diarrhoea if not by the surgeon, doubtless provide an opportunity for breaking old habits and forming new ones. Solow et al. (1974) administered a "cracker test" to their patients before and after jejeunoileostomy. Subjects were given free access to a variety of appetizing biscuits and were told that they were to select the tastiest as part of a consumer research project. The researchers were really interested in how many biscuits the subjects felt like eating, and this was studied both before and after a meal. They found some evidence that patients were more easily satiated postoperatively. Many of our patients who had a hearty appetite before jejeunoileostomy continued to eat heartily afterwards, however, and some patients who had followed a strict diet were pleased to find that they could now eat almost without restriction. Indeed, we have seen another patient who manifested something approaching compulsive eating for the first time after the operation, but this only lasted for about a month and was accompanied by pleasure rather than remorse.

Perhaps there is some paradoxical attraction in eating forbidden foods which disappears when, as a result of jejeunoileostomy, eating is no longer seen as a dangeous or guiltinducing pastime. Some regard compulsive eating in this context as a variety of self-punishing behaviour and since, like other authors (Harris and Frame, 1968; Solow et al., 1974), we have noted a considerable increase in self-confidence and assertiveness in most cases after jejeunoileostomy it may be that such patients no longer feel any overt or covert need to punish themselves. Perhaps the simplest hypothesis, however, is that eating is a tension-relieving device, and hence a misery-relieving or depression-relieving device; that the sprees are a direct consequence of depression- 
whether "endogenous" or "reactive" need not concern us here-and that the disappearance of the compulsion is a direct consequence of the improvement in mood. We would need to examine a group of compulsive eaters who remained depressed after jejeunoileostomy to test this hypothesis and so far we have not found such a combination of features. Certainly, this explanation would be consistent with the conclusion that depression accompanying obesity is often consequential rather than causal.

We thank Professor W. H. Trethowan for his helpful advice and Dr. Ellis Bindman for providing further information about case 6 .

\section{References}

Baddeley, R. M. (1973). Proceedings of the Royal Society of Medicine, 139, 1098.

British Medical fournal. (1974). 2, 575.

Eysenck, H. J., and Wilson, G. D. (1974). Experimental Study of Freudian Theories. London, Methuen.

Glucksman, M. L. (1972). Advances in Psychosomatic Medicine, 7, 194. Green, R., and Rau, J. (1974). American fournal of Psychiatry, 131, 4, 428. Harris, J., and Frame, B. (1968). Cited by Solow et al 1974.

Levitz, L. S., and Stunkard, A. J. (1974). American fournal of Psychiatry, $131,4,423$.

Payne, J. H., et al. (1973). Archives of Surgery, 106, 432.

Rachman, S. (1971). Effects of Psychotherapy. Oxford, Pergamon.

Solow, C., Silberfarb, P., and Swift, K. (1974). New England fournal of Medicine, 290, 300.

Wittkower, E. D. (1971). Psychosomatics, 12, 21.

\title{
Total Body Potassium in Long-Term Frusemide Therapy: Is Potassium Supplementation Necessary?
}

\author{
H. J. DARGIE, K. BODDY, \\ A. C. KENNEDY, \\ PRISCILLA C. KING, \\ P. R. READ, \\ D. M. WARD
}

British Medical fournal, 1974, 4, 316-319

\section{Summary}

Measurements of total body potassium (T.B.K.) were made by whole-body counting in four groups of patients receiving oral frusemide for one year. Patients in group 1 had essential hypertension and normal renal function and received $40 \mathrm{mg}$ frusemide daily without potassium supplements. Patients in group 2 were similar but received oral potassium supplements for the first four months of treatment. Patients in group 3 had hypertension associated with renal disease and received $120 \mathrm{mg}$ frusemide daily without potassium supplements. Patients in group 4 also had hypertension and renal impairment and in addition to $120 \mathrm{mg}$ frusemide daily they received oral potassium supplements for four months. No evidence of depletion of T.B.K. was found in any of the groups after continuous treatment with frusemide for one year. It is questioned whether potassium supplementation in long term diuretic therapy with frusemide is necessary unless there is evidence of pre-existing potassium depletion or of some other factor such as cardiac failure, cirrhosis of the liver, or the nephrotic syndrome.

\section{Introduction}

The development of hypokalaemia may complicate long-term diuretic therapy (Talso and Carballo, 1960; Remenchick et al., 1966; George et al., 1973), but since the total extracellular fluid space contains only $3 \%$ of the total body content of potassium plasma potassium levels may not accurately reflect the total body or intracellular potassium status (Healy et al., 1970; White,

University Department of Medicine, Royal Infirmary, Glasgow H. J. DARGIE, M.B., M.R.C.P., Medical Registrar (Present address: Royal Postgraduate Medical School, London)

A. C. KENNEDY, M.D., F.R.C.P., Professor of Medicine

P. R. READ, M.B., Clinical Research Assistant

Scottish Research Reactor Centre, East Kilbride

K. BODDY, B.SC., PH.D., Physicist

PRISCILLA C. KING, B.SC., PH.D., Physicist
1970; Flear, 1972; Graybiel and Sode, 1971). We therefore used the only direct method of estimating total body potassium (T.B.K.), whole-body counting, to assess the influence of longterm treatment with frusemide in patients with normal and diminished renal function. As potassium supplements are given customarily with diuretics, often without reference to the status of T.B.K., their effectiveness was also examined.

\section{Patients and Methods}

Twenty-nine patients, with their consent, were included in the study and were divided into four groups according to renal function and whether or not they were receiving potassium supplements. The clinical details are summarized in table I. Patients in group 1 had essential hypertension and normal renal function and were treated with frusemide $40 \mathrm{mg}$ daily for one year without potassium supplements. Patients in group 2 were similar but in addition to frusemide $40 \mathrm{mg}$ daily they received effervescent potassium chloride $24 \mathrm{mEq}$ daily for the first four months of treatment. Thereafter they continued on frusemide alone. Patients in group 3 had hypertension associated with renal disease, the range of endogenous creatinine clearance being $11-60 \mathrm{ml} / \mathrm{min}$ with a mean of $22 \mathrm{ml} / \mathrm{min}$. They received frusemide $120 \mathrm{mg}$ daily for one year without potassium supplements. Patients in group 4 also had renal impairment but had a higher mean rate of endogenous creatinine clearance $(43 \mathrm{ml} / \mathrm{min})$ and as well as frusemide $120 \mathrm{mg}$ daily they received effervescent potassium chloride $24 \mathrm{mEq}$ daily for the first four months and then continued on frusemide alone for a further eight months. None of the patients had cardiac failure or oedema of other origin and none had received a diuretic in the past two years. Other antihypertensive therapy was continued as before. No patients were receiving $\beta$-blocker drugs and the distribution of antihypertensive therapy was not dissimilar in the groups.

At the beginning of the study baseline measurements were made of T.B.K. and the plasma concentration of potassium, urea, creatinine, uric acid, blood sugar, chloride, and $\mathrm{CO}_{2}$. Blood pressure was also recorded using a standard cuff sphygmomanometer. The Merlin mobile whole-body counter (Boddy, 1967) was used to estimate T.B.K. by measuring the $1 \cdot 46-\mathrm{Mev}$ gamma-rays of the naturally occurring endogenous ${ }^{4} \mathrm{~K}$, which is a constant fraction of T.B.K. The calibration procedure described previously (Boddy et al., 1971) was applied. The coefficient of variation has been shown (Boddy et al., 1971) to be $2 \cdot 7 \%$ for the $70 \mathrm{~kg}$ man with $140 \mathrm{~g}$ potassium. The patients 